\title{
Case Report \\ Two-Step Extraction of the Lower First Molar for Class III Treatment in Adult Patient
}

\author{
Kélei Cristina de Mathias Almeida, ${ }^{1}$ Ricardo Fabris Paulin, ${ }^{2}$ Taísa Barnabé Raveli, ${ }^{1}$ \\ Dirceu Barnabé Raveli, ${ }^{1}$ and Ary Santos-Pinto ${ }^{1}$ \\ ${ }^{1}$ Department of Orthodontics and Pediatric Dentistry, Araraquara School of Dentistry, Universidade Estadual Paulista (UNESP), \\ Rua Humaitá 1680, 14801-903 Araraquara, SP, Brazil \\ ${ }^{2}$ Discipline de Occlusion and Orthodontics, Paulista University (UNIP), SGAS 913, Asa Sul, 71918-000 Brasília, DF, Brazil
}

Correspondence should be addressed to Ary Santos-Pinto; spinto@foar.unesp.br

Received 4 April 2016; Accepted 13 July 2016

Academic Editor: Mohammad Hosein K. Motamedi

Copyright (C) 2016 Kélei Cristina de Mathias Almeida et al. This is an open access article distributed under the Creative Commons Attribution License, which permits unrestricted use, distribution, and reproduction in any medium, provided the original work is properly cited.

\begin{abstract}
The aim of this article is to describe a case report of Class III malocclusion treatment with lower first molar extraction. The 27-yearold Caucasian male patient presented a symmetric face with a straight profile, hyperdivergent growth pattern, molar and cuspid Class III relation, and an anterior crossbite as well as a mild crowding on cuspids area, in both upper and lower arches and a tendency to posterior crossbite. The treatment was performed by the use of Haas expansion appliance followed by an initial alignment and leveling of the upper and lower arches with a fixed edgewise appliance, extraction of lower teeth aiming the correction of the incisors proclination and end the treatment with a Class I molar relationship. It resulted in a significant change in the patient's profile, dentoalveolar Class III correction, upper arch expansion, leveling and alignment of the upper and lower arches, and improvement of tipping of the upper and lowers incisors. In cases of a dentoalveolar compensation in well positioned bone bases the treatment with fixed appliances is an alternative and extraction of lower teeth is considered.
\end{abstract}

\section{Introduction}

Treatment for Class III malocclusion is still challenging for orthodontists and moreover for adult patients that present skeletal concern and wish conservative approach [1]. Fortunately, the malocclusion Class III represents a small percentage of all malocclusions among orthodontic patients [2]. The prevalence of this malocclusion was reported between $1 \%$ $[3,4]$ and $10 \%[2]$, depending on ethnic origin $[4,5]$, gender $[1,6]$, and age [7], as well as the diagnostic criteria [8].

For adult patients with this malocclusion, there are two main treatment options: dental compensation and orthognathic surgery $[1,9-13]$. The value of skeletal discrepancies usually determines whether a surgical correction is appropriate. However, in borderline cases, a balance of soft profile will help determine whether patients can deal with dental compensation [14].
A treatment option for patients that are reluctant to undergo surgery or that are satisfied with their facial appearance is dentoalveolar compensation without skeletal correction [1]. In general, fixed appliances with extractions are considered the best option for adult Class III nonsurgical treatment [14].

Traditionally, the extraction of four premolars (first lower and upper seconds) is the most common option; however, other choices extractions can also be used [15-17]. When lower third molars are present, the extraction of lower first molars can be considered for Class III treatment as long as they present one or more of the following conditions: root canal treatment, large cavities, severe periodontal disease, and extensive restoration [18].

This treatment option corrects the molar sagittal position, providing a Class I relationship between upper first molars and lower second and mesial placement of these teeth can 

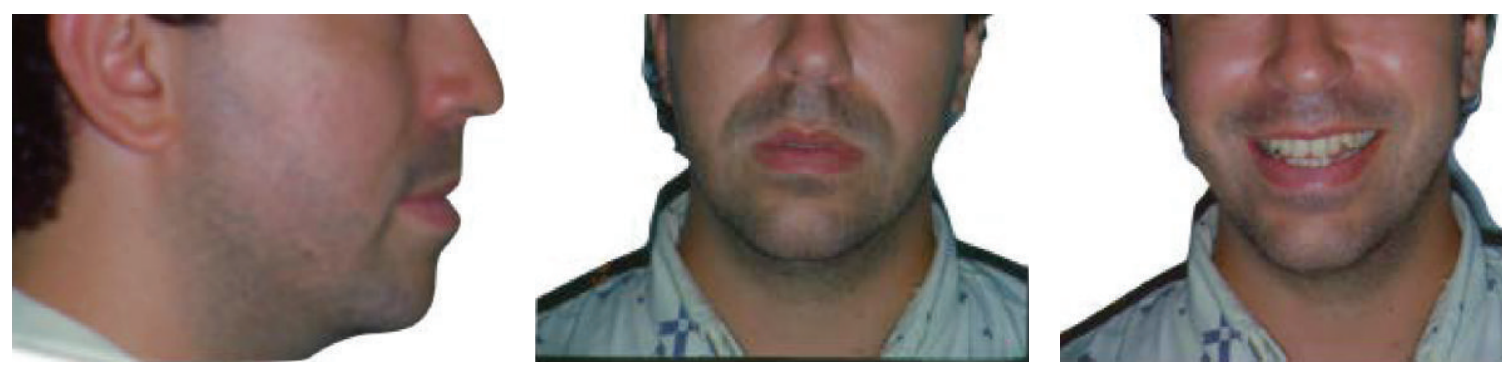

FIGURE 1: Patient with symmetric face with a convex profile and a hyperdivergent growth pattern.

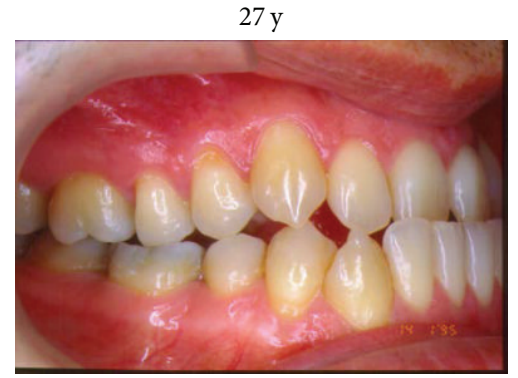

(a)

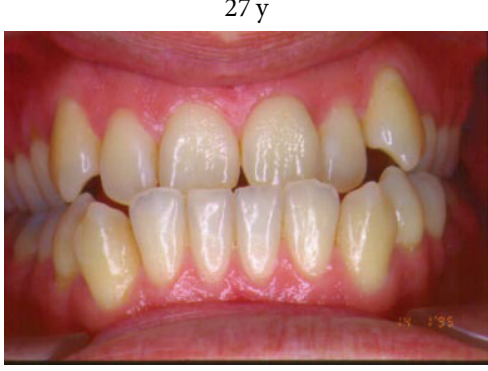

(b)

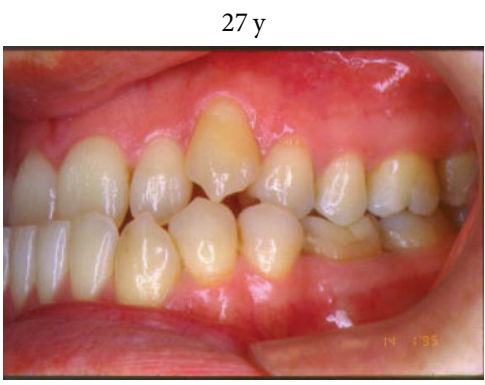

(c)

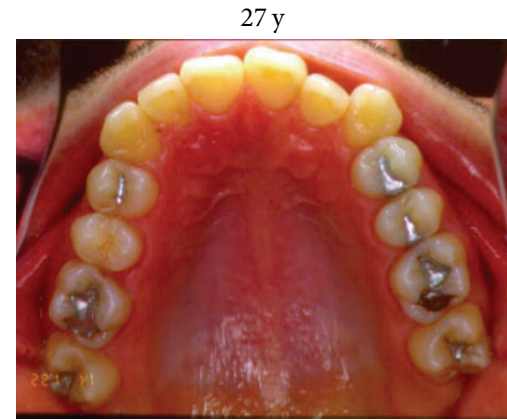

(d)

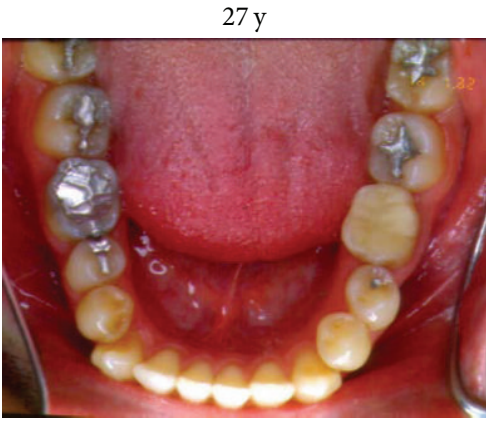

(e)

FIgURE 2: Intraoral exam: (a) molar and cuspid Class III relation; (b) anterior crossbite; (c) tendency to posterior crossbite; (d, e) mild crowding on cuspids area in both upper and lower arches.

facilitate anticlockwise mandibular rotation. However, this treatment approach is not indicated for all patients for it requires an additional orthodontic biomechanics to manage first molar space closure which takes very long. Also, lower second molars tend to tip mesially and lingually.

The aim of this paper is to present a case report in which a Class III malocclusion was treated with first lower molars extraction and complete fixed appliances.

\section{Clinical Case}

During clinical examination, it was observed that the 27year-old caucasian male patient presented a symmetric face with a convex profile and a hyperdivergent growth pattern (Figure 1). The intraoral exam revealed a molar and cuspid Class III relation and an anterior crossbite as well as a mild crowding on cuspids area in both upper and lower arches and a tendency to posterior crossbite (Figure 2).
Panoramic X-ray showed integrity of the permanent teeth and absence of upper third molars although the lower third molars were present and already erupted into the arch (Figure 3(a)). The cephalometric analysis showed a severe vertical pattern, convex profile, increased lower facial height, a slightly retruded maxilla in relation to the cranial base, and a well-positioned mandible (Figure 3(b)). The upper incisors were in a good inclination while the lower incisors were uprighted. The cephalometric data are showed in Table 1.

According to cephalometric analysis, the diagnosis was dentoalveolar Class III with anterior crossbite. The initial treatment plan consisted of palatal expansion followed by fixed appliances on both arches, with a probable extraction of lower teeth.

The treatment was conducted initially by the use of Haas expansion appliance (Figure 4(a)) followed by an initial alignment and leveling of the upper and lower arches with a fixed edgewise appliance. The aim of using the Haas appliance 


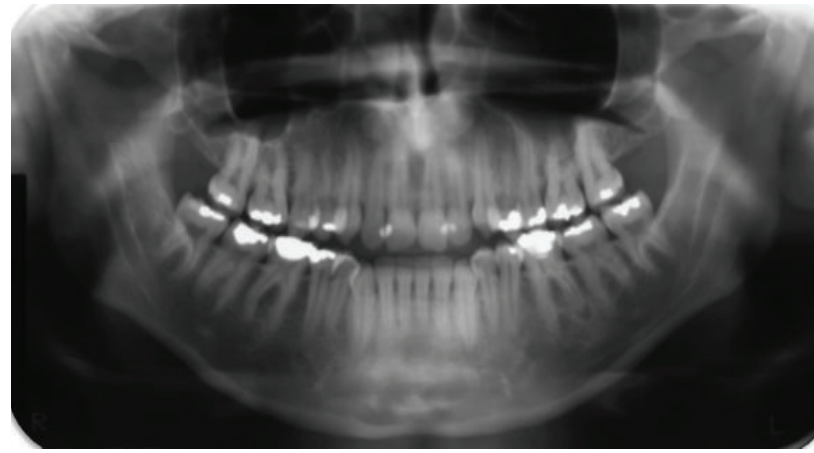

(a)

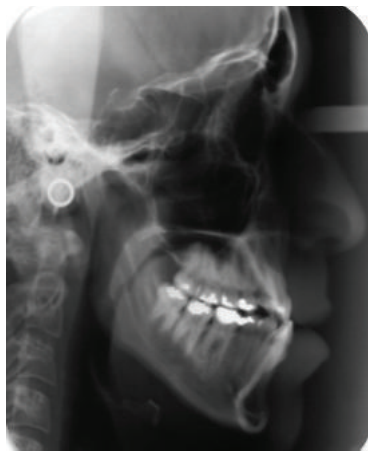

(b)

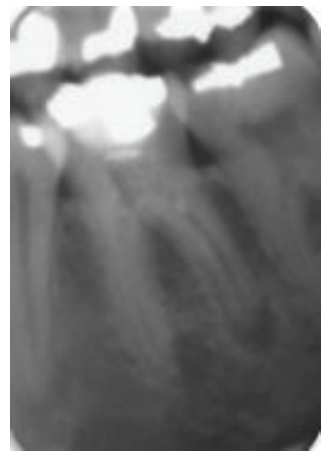

(c)

Figure 3: (a) Panoramic X-ray showed integrity of the permanent teeth and absence of upper third molars; (b) cephalometric analysis showed a severe vertical pattern, convex profile, increased lower facial height, a slightly retruded maxilla in relation to the cranial base, and a wellpositioned mandible. The upper incisors were in a good inclination while the lower incisors were uprighted; (c) endodontic lesion in tooth 36.
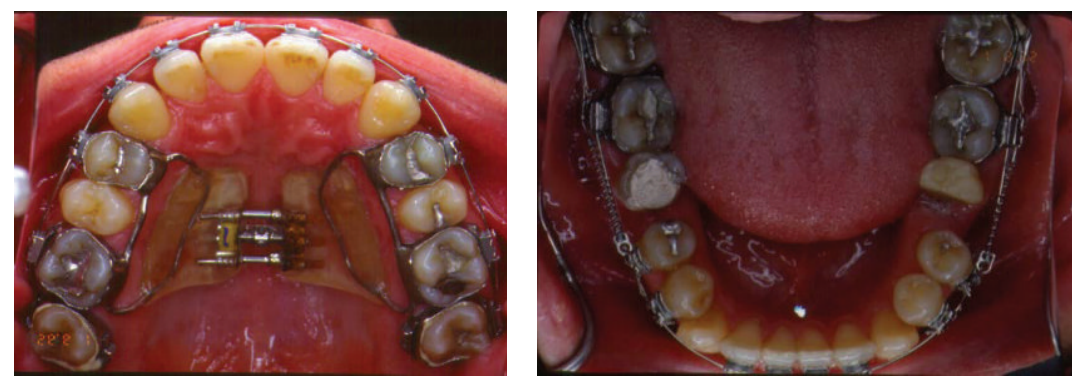

(a)
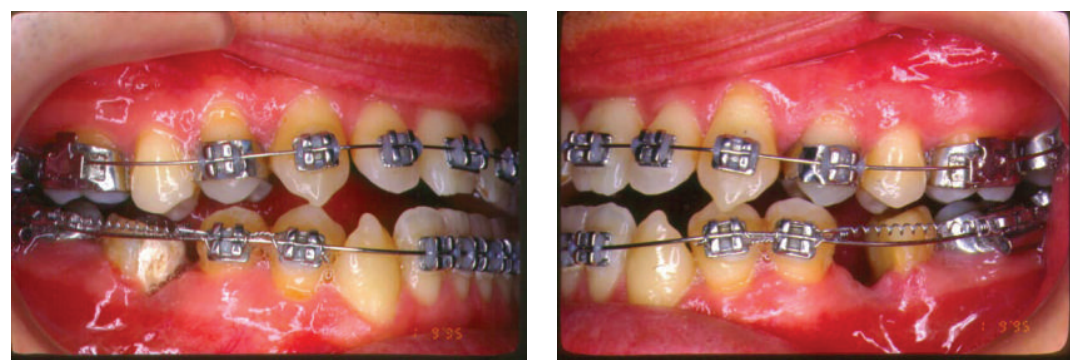

(b)
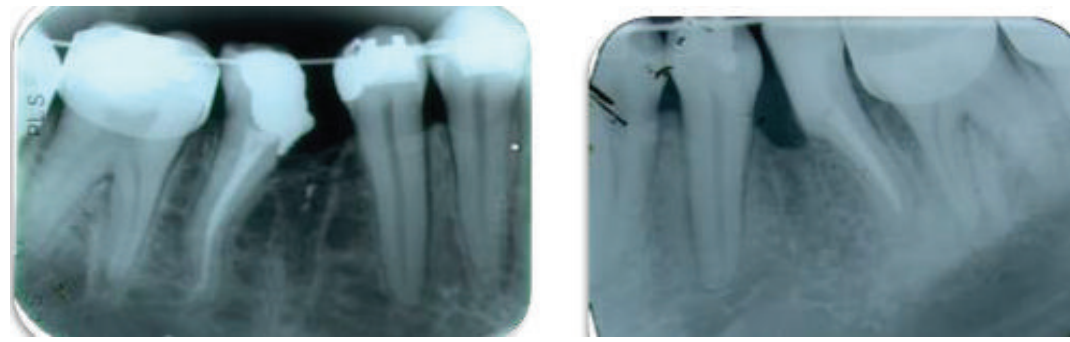

(c)

Figure 4: (a) The treatment was conducted initially by the use of Haas expansion appliance; (b, c) the extraction was performed in two steps, first with the extraction of the mesial root of the first molar, followed by the extraction of the distal root after closing the resultant space with a retraction loop. 
TABLE 1: Cephalometric analysis.

\begin{tabular}{lccc}
\hline Cephalometric data & Standard values of Caucasian & Pretreatment & Posttreatment \\
\hline SNA & $82^{\circ} \pm 2^{\circ}$ & $79.0^{\circ}$ & $81.0^{\circ}$ \\
SNB & $80^{\circ} \pm 2^{\circ}$ & $79.0^{\circ}$ & $79.0^{\circ}$ \\
ANB & $2^{\circ} \pm 2^{\circ}$ & $0^{\circ}$ & $2.0^{\circ}$ \\
SND & $76^{\circ} / 77^{\circ}$ & $77.0^{\circ}$ & $77.0^{\circ}$ \\
Mand. plane & $32^{\circ}$ & $42.0^{\circ}$ & $39.0^{\circ}$ \\
SNOP & $14^{\circ}$ & $15.4^{\circ}$ & $12.6^{\circ}$ \\
\hline l.NA & $22^{\circ}$ & $22.0^{\circ}$ & \\
l-NA & $4 \mathrm{~mm}$ & $7.0 \mathrm{~mm}$ & $18.0^{\circ}$ \\
l.NB & $25^{\circ}$ & $28.0^{\circ}$ & $6.0 \mathrm{~m}$ \\
l-NB & $4 \mathrm{~mm}$ & $9.0 \mathrm{~mm}$ & $18.0^{\circ}$ \\
CoA & $83 \mathrm{~mm}$ & $91.0 \mathrm{~mm}$ & $5.0 \mathrm{~m}$ \\
CoGn & $100 \mathrm{~mm}$ & $131.0 \mathrm{~mm}$ & $92.1 \mathrm{~mm}$ \\
LAFH & $57-59 \mathrm{~mm}$ & $81.0 \mathrm{~mm}$ & $131.1 \mathrm{~mm}$ \\
Facial angle & $90^{\circ} \pm 3^{\circ}$ & $90.0^{\circ}$ & $82.5 \mathrm{~mm}$ \\
A-Nperp & $0-1 \mathrm{~mm}$ & $-0.9 \mathrm{~mm}$ & $90.0^{\circ}$ \\
Pg-Nperp & $0 \pm 2 \mathrm{~mm}$ & $-3.0 \mathrm{~mm}$ & $-3.0 \mathrm{~mm}$ \\
H line & $9 \mathrm{a} 11 \mathrm{~mm}$ & $5.0 \mathrm{~mm}$ & $9.0 \mathrm{~mm}$ \\
\hline
\end{tabular}
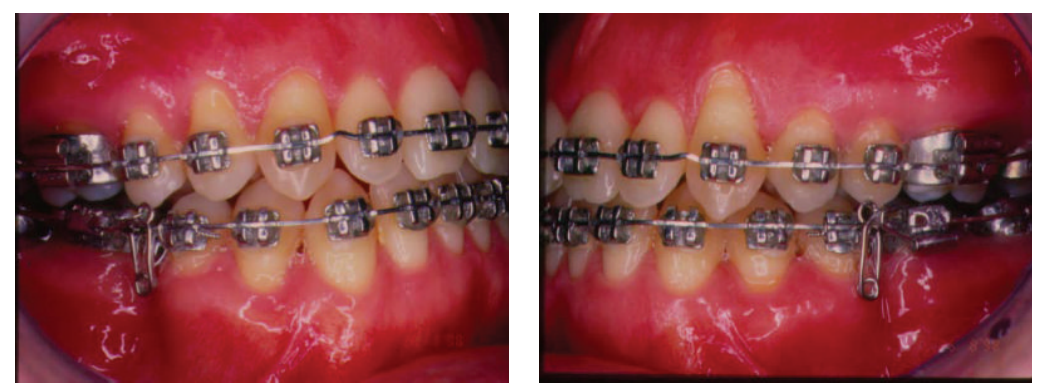

(a)

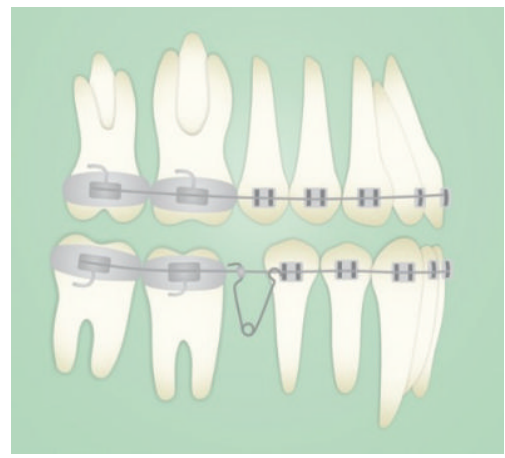

(b)

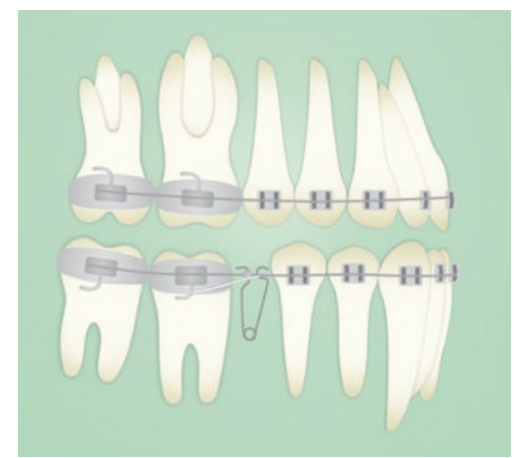

(c)

Figure 5: After the alignment of the lower anterior segment, an $\mathrm{H}$ loop was inserted to finish the space closure by second molars avoiding its tipping. Class III elastics were used during this phase of the treatment.

was just a dentoalveolar expansion as the patient was an adult so there was no possibility of opening the midpalatal suture. A 5/16 Class III elastic with 8 ounces was used associated with a lip bumper in order to achieve maxilla dentoalveolar protraction.

In order to correct the anterior crossbite, the treatment plan would include the extraction of lower teeth. So it was decided for the extraction of the lower first molars, as the lower third molars were present while there were no upper third molars, aiming at the correction of the incisors proclination and end the treatment with a Class I molar relationship. The extraction was performed in two steps, first with the extraction of the mesial root of the first molar (Figures 4(b) and $4(\mathrm{c})$ ) followed by the extraction of the distal root after 


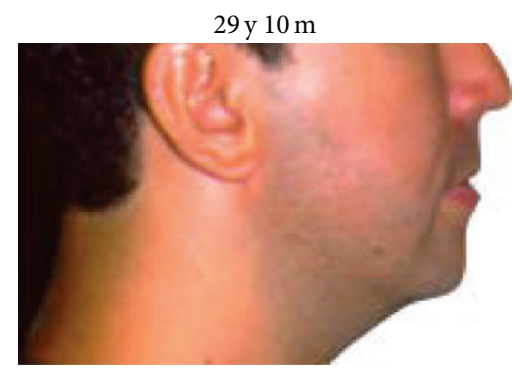

(a)

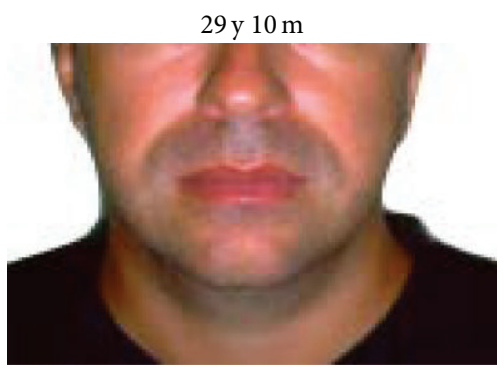

(b)

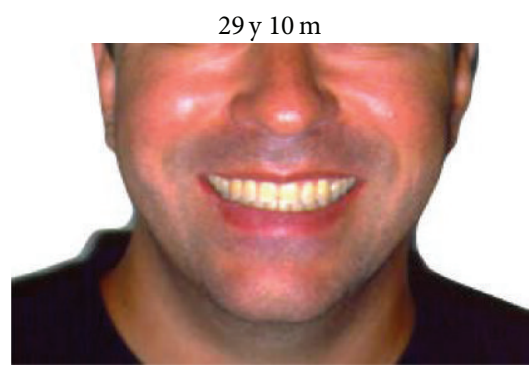

(c)

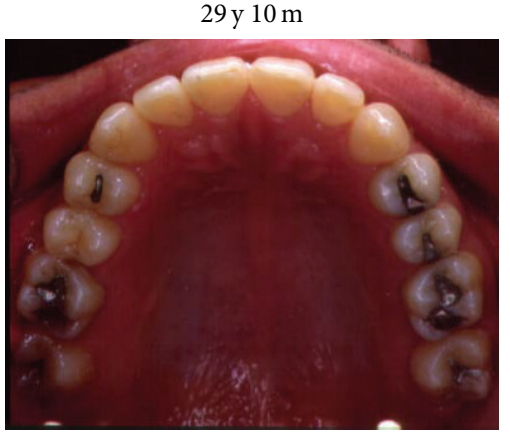

(d)

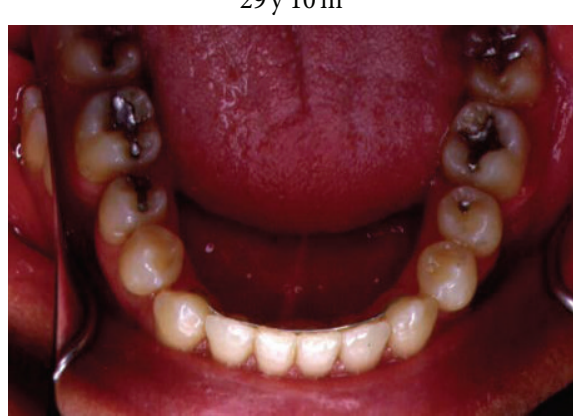

(e)

29 y $10 \mathrm{~m}$

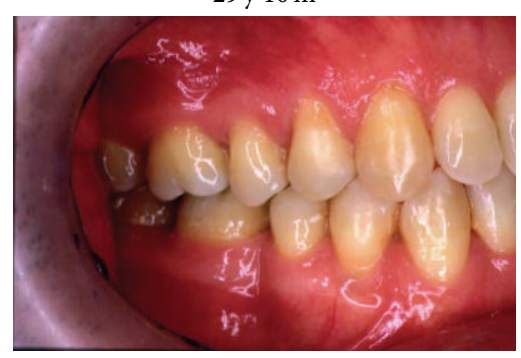

(f)

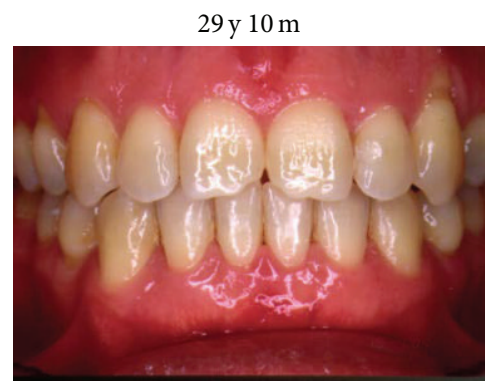

(g)

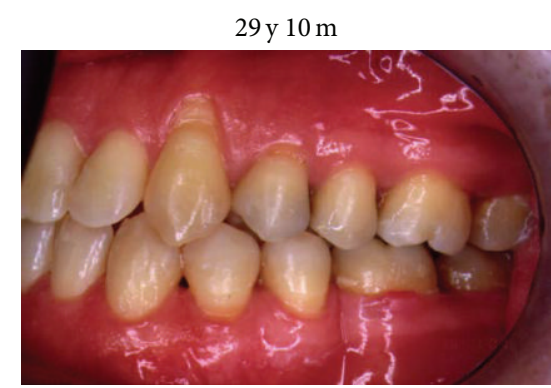

(h)

Figure 6: $(a, b, c)$ Alteration in the patient's profile after treatment, dentoalveolar Class III correction, upper arch expansion, and leveling and alignment of the upper and lower arches; $(\mathrm{d}, \mathrm{e}, \mathrm{f}, \mathrm{g}, \mathrm{h})$ intraoral pictures after complete treatment.

closing the resultant space with a retraction loop. These two steps of extraction were done to avoid anchorage loss and tipping of second molars in the first moment when premolars were retracted to open space for canine alignment. For that purpose, it was used a closed NiTi coil spring ( $250 \mathrm{gr}$ ) applied from the second molar to the second premolar, which was tied together to the first premolar. After the alignment of the lower anterior segment, an H loop (Figure 5) was inserted in order to finish the space closure by second molars mesial movement avoiding its tipping. Class III elastics were used during this phase of the treatment.

The treatment resulted in a significant alteration in the patient's profile (Figures 6(a)-6(c)), dentoalveolar Class III correction, upper arch expansion, and leveling and alignment of the upper and lower arches (Figures 6(d)-6(h)). A slight protrusion was also observed and lingual tipping of the upper and slight retraction and lingual tipping lower incisors dental compensation for unfavorable skeletal discrepancy the final lateral radiograph analysis (Figures $7(\mathrm{a})$ and $7(\mathrm{~b})$ ) are presented in Table 1. An upper removable appliance and a 3-3 lower retainer were used for retention (Figure 7(c)).

Figure 8 summarizes the treatment with Hass expansion appliance that was carried out as 1 turn per day $(0.2 \mathrm{~mm})$ during 2 weeks and the appliance was kept in retention for 4 months. Mesial root extraction was performed after 2 months of treatment. The first phase of the space closure occurred at 12 months with retraction of the premolars to align anterior teeth. The distal root extraction was performed after 14 months of treatment. The second phase of the space closure occurred at 10 months with molars mesialization. Finalization and intercuspidation occurred during 8 months. Total treatment time was 34 months.

\section{Discussion}

When Class III malocclusion treatment starts up after the facial growth, the options are more limited; usually tooth 


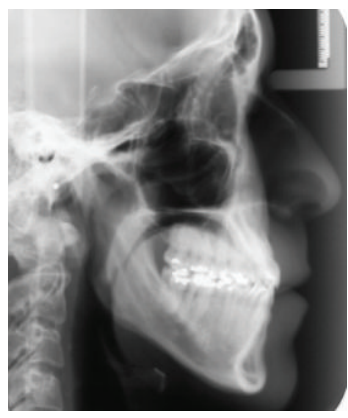

(a)

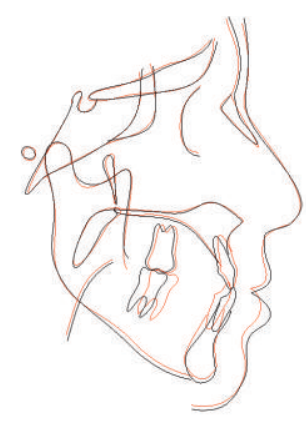

(b)

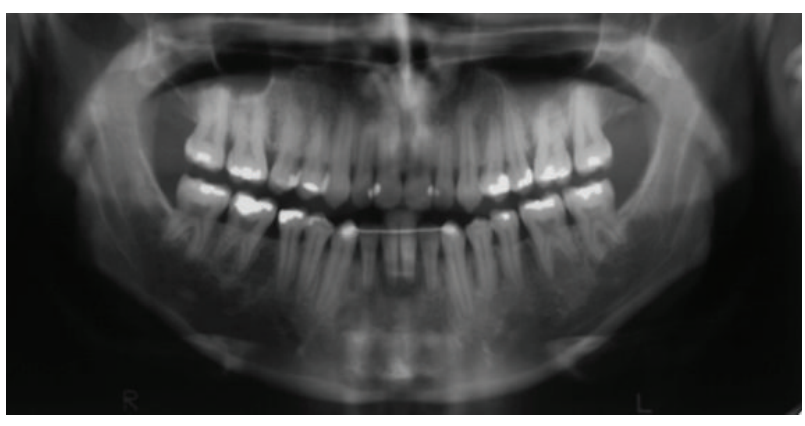

(c)

Figure 7: (a, b) Movements of the upper and lower incisors can be noted in the cephalometric X-ray; (c) Upper removable appliance and a 3-3 lower retainer used for retention.

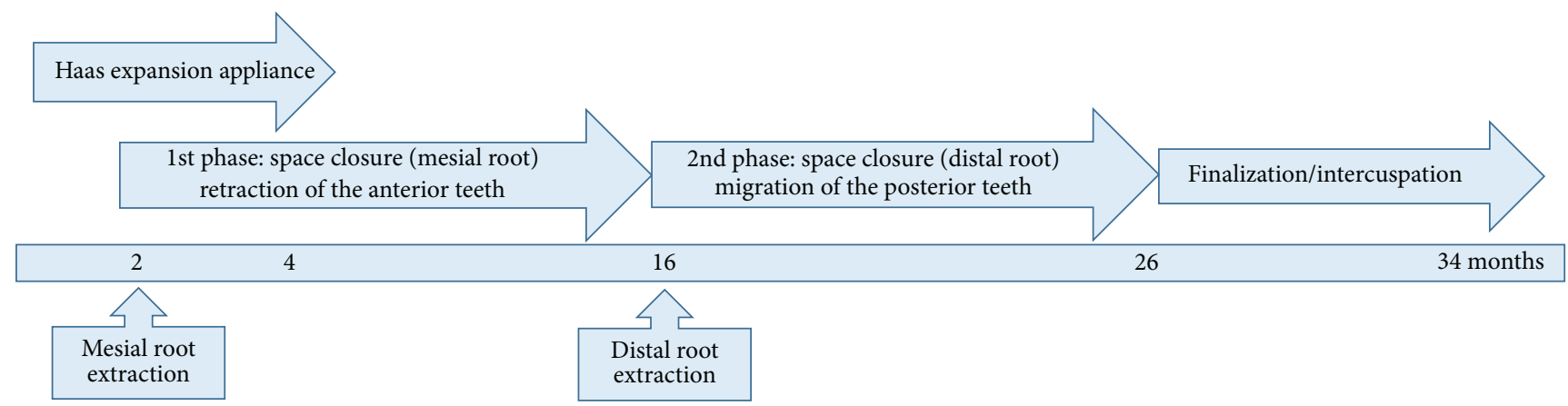

FIGURE 8: Flowchart of treatment with Haas expansion appliance.

extraction associated with orthodontic mechanics is considered the only option for nonsurgical treatment [14].

Usually the extraction of the four premolars would be the first choice, but the first molars may be an option when they have endodontic treatment, large cavities of caries, severe periodontal involvement, and extensive restorations. Other situations in which first molars can be extracted are hypoplastic lesion, apical pathology, and lower anterior teeth crowding [18].

This case was conducted with extraction of the first molars because they presented extensive restorations and the lower left first molar (36) showed a periapical lesion in the distal root. It was also considered the absence of up third molars, invigorating this diagnosis. Among the advantages of opting for such conduct, it is the Class I dental relationship (molar and canine), established by the second molars, but among the disadvantages, there are more complicated orthodontic mechanics and prolonged duration of treatment [19].

The upper dental crowding was treated with the rapid expansion of the arc with Haas appliance (Figure 4). This therapy promoted the increase of the arch perimeter with vestibular inclination of posterior teeth without moving the anterior teeth to this sense. In adults, increased skeletal transverse dimension of the palate promoted by ERM is small $[20,21]$, being predominantly dentoalveolar. In this case, changing the positioning of the maxillary bone may have occurred, most likely due to an "alveolar bone remodeling," resulting sagittal change of point $\mathrm{A}$, changeable with orthodontic therapy [22].

The cephalometric superimposition (Figures 7(a) and 7(b)) shows that the molar inclined to mesial position, but this movement was controlled by segment extraction of the first molars roots. The extraction of the first molars mesial root allowed the alignment and correction of overjet, while the extraction of the distal roots allowed establishing a class I relationship of canines and the remaining space enclosed by mesialization of the second molar with spring $\mathrm{H}$ support. The disadvantage of this procedure was the need for endodontic treatment of these teeth.

Changes in positions of lower incisors were significant, where there was a lingualization, extrusion, and retraction with alveolar remodeling. Also, the mesial movements of the molars produced a mild anticlockwise rotation of the plans occlusal and mandibular [16].

As only the first lower molars were extracted, avoiding significant changes in the upper lip, it would be undesirable for the facial profile of this patient. Labial movement of the upper incisors was achieved by the use of the Class III elastics during all phases of treatment.

After the end of orthodontic treatment, in the extraction sites, it is common to find interdental gingival crevicular [14, 23]. These are defined as mesial and distal tissue invagination having a depth of, at least, $1 \mathrm{~mm}$ [24]. The presence of these 
crevices may have clinical implications, not only in terms of orthodontic recurrence but also to maintain the periodontal health. Thus, performing surgery to prevent opening interdental space and maintain periodontal health is shown $[25,26]$.

In the case described here, there was no sagital skeletal component, although the patient presented an increased lower facial height. As there was no intention of a surgical approach, an extraction therapy was considered a viable option.

The treatment was successfully conducted. There was the correction of the anterior crossbite, tendency of posterior crossbite, and molar/cuspid relationship. The enhancement of the facial profile was also observed.

\section{Conclusion}

The Class III treatment in adult patients is very complicated and often requires surgical correction. But it is known that in some situations instead of a skeletal dysplasia there is a dentoalveolar compensation in well positioned bone bases. In these cases the treatment with fixed appliances is an alternative, and in some instances, extraction of lower teeth is considered.

\section{Competing Interests}

The authors declare that there is no conflict of interests regarding the publication of this paper.

\section{References}

[1] G. Janson, J. E. Prado De Souza, F. De Andrade Alves et al., "Extreme dentoalveolar compensation in the treatment of Class III malocclusion," American Journal of Orthodontics and Dentofacial Orthopedics, vol. 128, no. 6, pp. 787-794, 2005.

[2] N. H. El-Mangoury and Y. A. Mostafa, "Epidemiologic panorama of dental occlusion," Angle Orthodontist, vol. 60, no. 3, pp. 207-214, 1990.

[3] I. N. Hill, J. R. Blayney, and W. Wolf, “The Evanston Dental Caries study: XIX. Prevalence of malocclusion of children in a fluoridated and control area," Journal of Dental Research, vol. 38, no. 4, pp. 782-794, 1959.

[4] R. E. Emrich, A. G. Brodie, and J. R. Blayney, "Prevalence of Class 1, Class 2, and Class 3 malocclusions (Angle) in an urban population. An epidemiological study," Journal of Dental Research, vol. 44, no. 5, pp. 947-953, 1965.

[5] T. Endo, "An epidemiological study of reversed occlusion. I. Incidence of reversed occlusion in children 6 to 14 years old," The Journal of Japan Orthodontic Society, vol. 30, no. 1, pp. 7377, 1971.

[6] T. Baccetti, B. C. Reyes, and J. A. McNamara Jr., "Gender differences in Class III malocclusion," The Angle Orthodontist, vol. 75, no. 4, pp. 510-520, 2005.

[7] B. Thilander, L. Pena, C. Infante, S. S. Parada, and C. De Mayorga, "Prevalence of malocclusion and orthodontic treatment need in children and adolescents in Bogota, Colombia. An epidemiological study related to different stages of dental development," European Journal of Orthodontics, vol. 23, no. 2, pp. 153-167, 2001.
[8] C. B. Staudt and S. Kiliaridis, "Divergence in prevalence of mesiocclusion caused by different diagnostic criteria," American Journal of Orthodontics and Dentofacial Orthopedics, vol. 135, no. 3, pp. 323-327, 2009.

[9] S. Kuroda, Y. Sugawara, K. Yamashita, T. Mano, and T. TakanoYamamoto, "Skeletal Class III oligodontia patient treated with titanium screw anchorage and orthognathic surgery," American Journal of Orthodontics and Dentofacial Orthopedics, vol. 127, no. 6, pp. 730-738, 2005.

[10] A. T. Moullas, J. M. Palomo, J. R. Gass, B. D. Amberman, J. White, and D. Gustovich, "Nonsurgical treatment of a patient with a Class III malocclusion," American Journal of Orthodontics and Dentofacial Orthopedics, vol. 129, no. 4, pp. S111-S118, 2006.

[11] L. D. Toffol, C. Pavoni, T. Baccetti, L. Franchi, and P. Cozza, "Orthopedic treatment outcomes in Class III malocclusion," The Angle Orthodontist, vol. 78, no. 3, pp. 561-573, 2008.

[12] N. R. Burns, D. R. Musich, C. Martin, T. Razmus, E. Gunel, and P. Ngan, "Class III camouflage treatment: what are the limits?" American Journal of Orthodontics and Dentofacial Orthopedics, vol. 137, no. 1, pp. 9.el-9.e13, 2010.

[13] R. Islam, T. Kitahara, L. Naher, A. Hara, and S. Nakata, "Lip morphology changes following orthognathic surgery for class III malocclusion," The Angle Orthodontist, vol. 80, no. 2, pp. 344-353, 2010.

[14] A. C. Ruellas, C. Baratieri, M. B. Roma et al., "Angle Class III malocclusion treated with mandibular first molar extractions," American Journal of Orthodontics and Dentofacial Orthopedics, vol. 142, no. 3, pp. 384-392, 2012.

[15] J. L. Seddon, "Extraction of four first molars: a case for a general practitioner?" Journal of Orthodontics, vol. 31, no. 2, pp. 80-85, 2004.

[16] J. Lin and Y. Gu, "Lower second molar extraction in correction of severe skeletal class III malocclusion," The Angle Orthodontist, vol. 76, no. 2, pp. 217-225, 2006.

[17] I. Saito, M. Yamaki, and K. Hanada, "Nonsurgical treatment of adult open bite using edgewise appliance combined with highpull headgear and Class III elastics," The Angle Orthodontist, vol. 75, no. 2, pp. 277-283, 2005.

[18] M. A. Schroeder, D. K. Schroeder, D. J. S. Santos, and M. M. Leser, "Molar extractions in orthodontics," Dental Press Journal of Orthodontics, vol. 16, no. 6, pp. 130-157, 2012.

[19] E. A. Araújo and C. V. Araújo, "Abordagem clínica nãocirúrgica no tratamento da má oclusão de Classe III," Revista Dental Press de Ortodontia e Ortopedia Facial, vol. 13, no. 6, pp. 128-157, 2008.

[20] W. H. Bell and B. N. Epker, "Surgical-orthodontic expansion of the maxilla," American Journal of Orthodontics, vol. 70, no. 5, pp. 517-528, 1976.

[21] C. S. Handelman, L. Wang, E. A. BeGole, and A. J. Haas, "Nonsurgical rapid maxillary expansion in adults: report on 47 cases using the haas expander," Angle Orthodontist, vol. 70, no. 2, pp. 129-144, 2000.

[22] E. Prado, "Questionando paradigmas no tratamento da Classe III em adultos. Qual seria o limite da compensação em pacientes adultos?" Revista Clínica de Ortodontia, vol. 6, no. 3, pp. 16-29, 2007.

[23] A. L. Rivera Circuns and J. F. C. Tulloch, "Gingival invagination in extraction sites of orthodontic patients: their incidence, effects on periodontal health, and orthodontic treatment," American Journal of Orthodontics, vol. 83, no. 6, pp. 469-476, 1983. 
[24] P. B. Robertson, L. D. Schultz, and B. M. Levy, "Occurrence and distribution of interdental gingival clefts following orthodontic movement into bicuspid extraction sites," Journal of Periodontology, vol. 48, no. 4, pp. 232-235, 1977.

[25] S. Malkoc, T. Buyukyilmaz, I. Gelgor, and M. Gursel, "Comparison of two different gingivectomy techniques for gingival cleft treatment," Angle Orthodontist, vol. 74, no. 3, pp. 375-380, 2004.

[26] M. L. B. Pinheiro, T. C. Moreira, and E. J. Feres-Filho, "Guided bone regeneration of a pronounced gingivo-alveolar cleft due to orthodontic space closure," Journal of Periodontology, vol. 77, no. 6, pp. 1091-1095, 2006. 


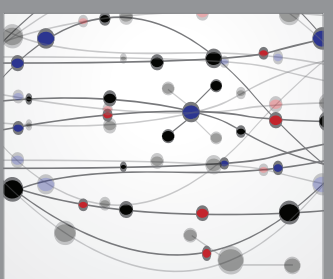

The Scientific World Journal
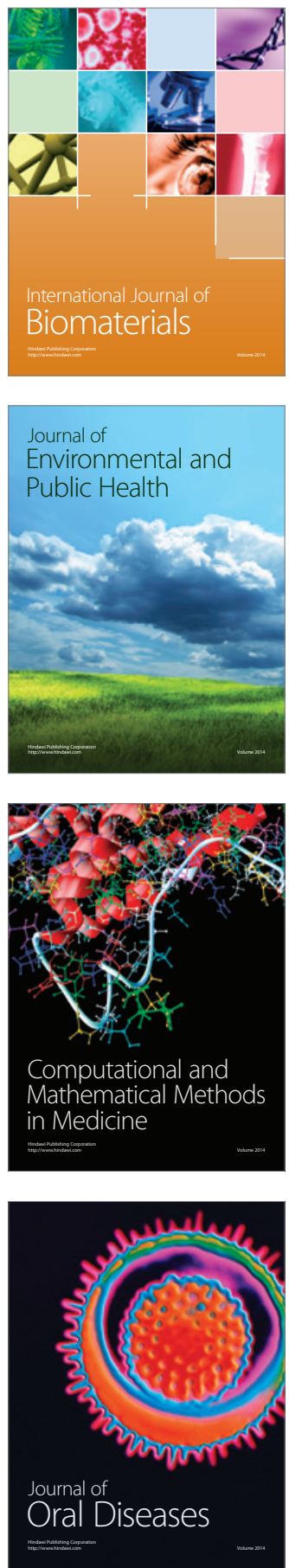
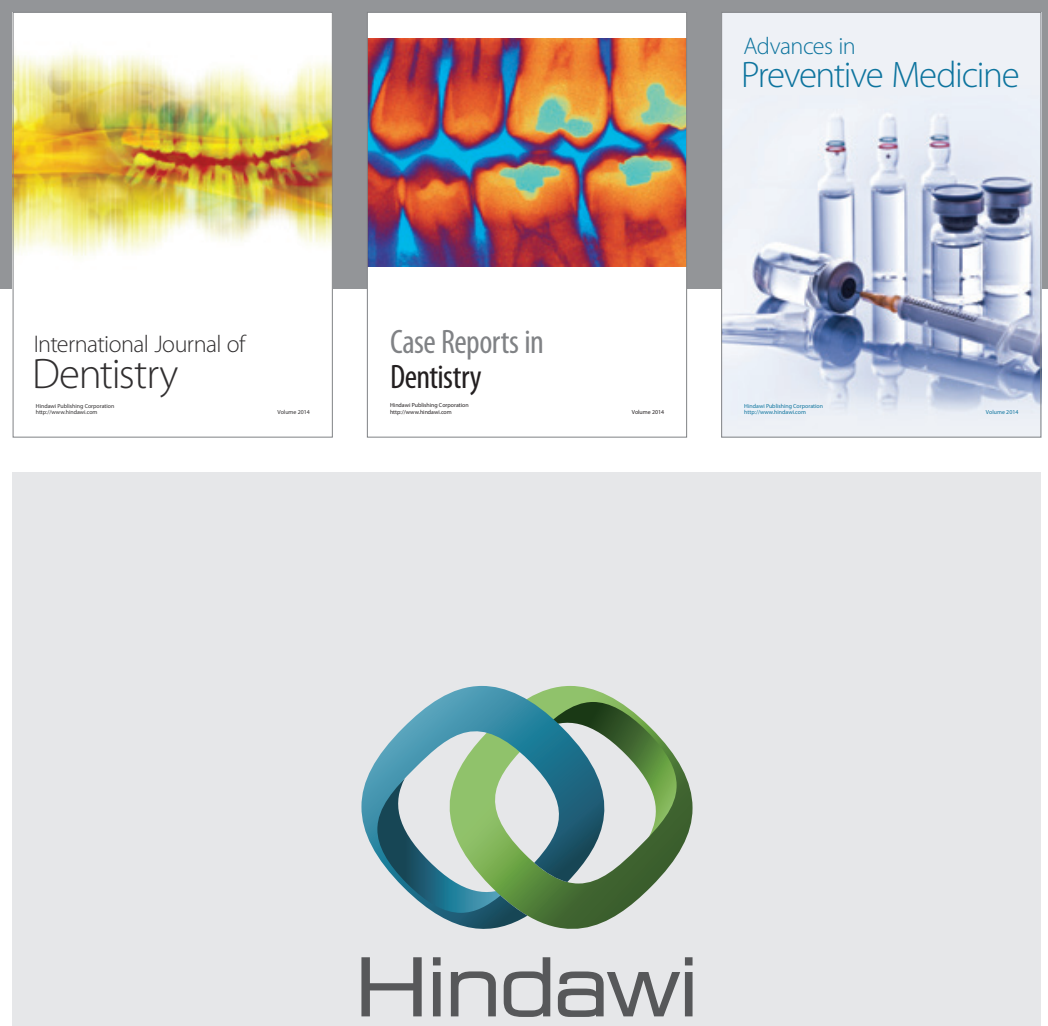

Submit your manuscripts at

http://www.hindawi.com
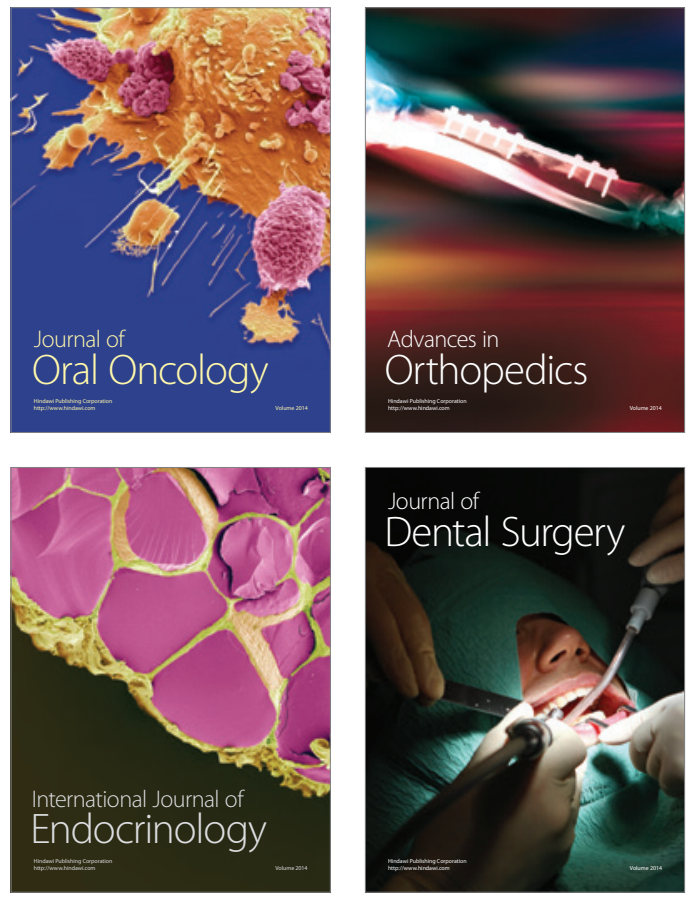
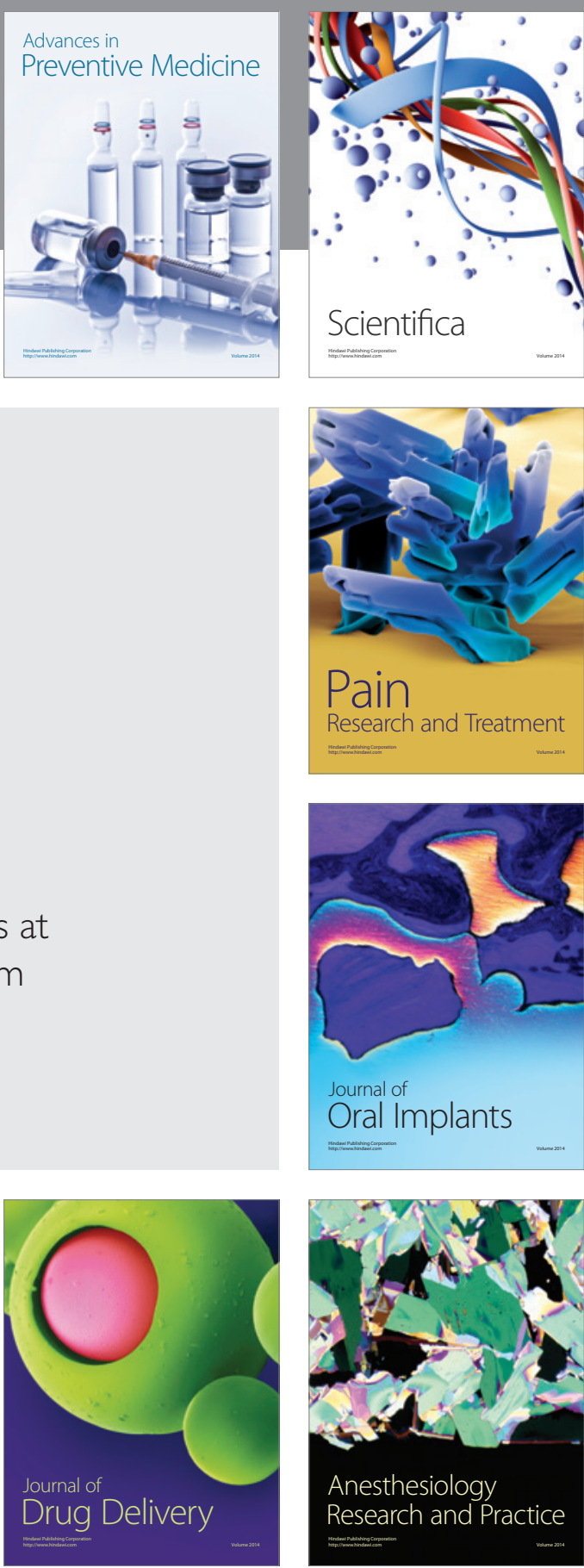

Scientifica
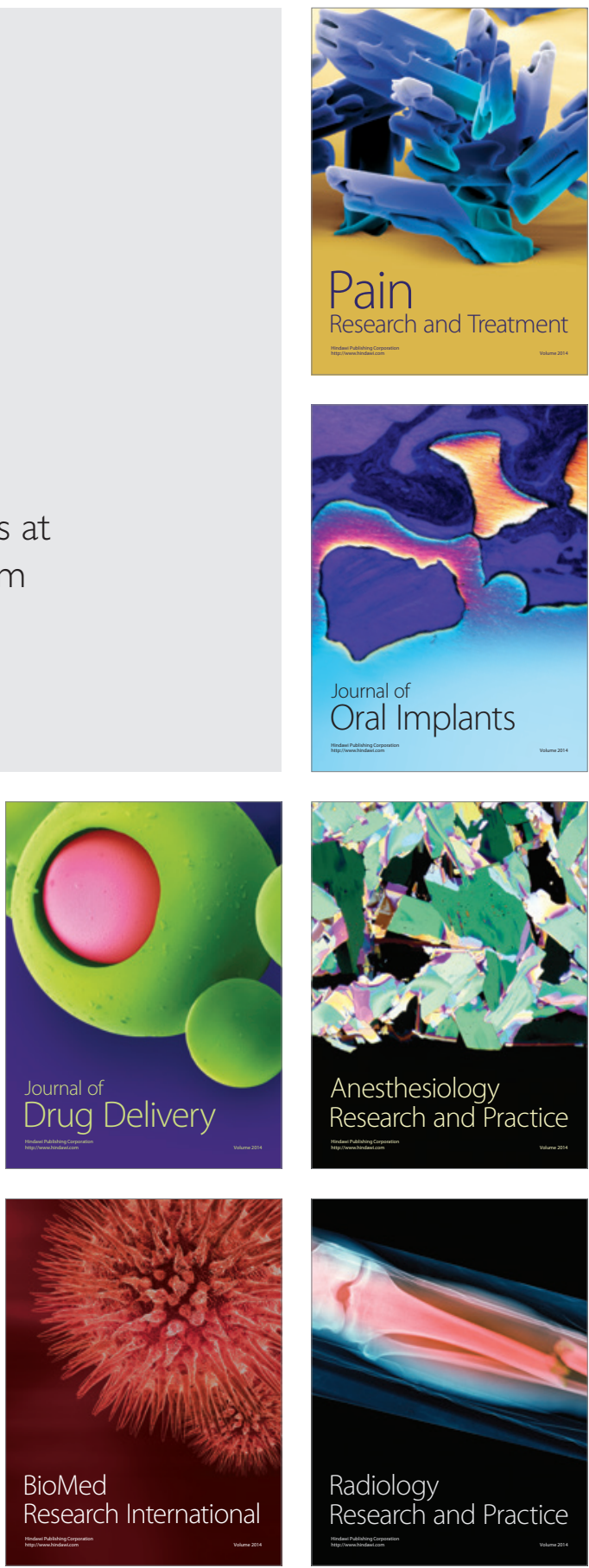